\title{
STAKEHOLDERS DA BOVINOCULTURA DE CORTE SUSTENTÁVEL NO BRASIL
}

\author{
Denise Barros de Azevedo* \\ Raissa Macedo Lacerda Osorio** \\ Roberta Dalla Porta Grundling*** \\ Guilherme Cunha Malafaia** \\ Vinicius Castro Domingues****** \\ Lucas Borges Silva******
}

RESUMO: A preocupação com a sustentabilidade, que emergiu principalmente a partir de eventos internacionais, passou a ser visível também na política em geral e nas estruturas de governo, sendo notável o esforço em vincular discursos políticos com a noção de sustentabilidade. Porém, o que a sociedade realmente anseia é pela prática do discurso, por um mundo em que as dimensões da sustentabilidade sejam reconhecidas, discutidas e respeitadas. Neste ínterim, este artigo tem como objetivo identificar as principais discussões em torno da temática da sustentabilidade e os stakebolders que as conduzem na Câmara Setorial da cadeia produtiva da carne bovina no Brasil nos últimos cinco anos. Para tal, foi realizada uma análise qualitativa em torno dos diálogos e ações na referida Câmara Setorial. Esta pesquisa lançou mão do método de análise de conteúdo (BARDIN, 2006), por meio do qual foram definidas categorias de análise a priori, à luz da literatura. Foram atas de 16 reuniões, embora tenham acontecido, no total, 18 reunióes no período considerado. Como resultados, foi percebida uma preocupação maior em torno da dimensão ecológica da sustentabilidade, enquanto que as outras dimensões foram pouco ou nada discutidas. A análise das atas e pautas, porém, indica que essa temática já estava definida em pauta, o que pode auxiliar a compreensão dos assuntos debatidos nas reuniões analisadas. Percebeu-se que as discussões em torno de todas as questões envolvendo a sustentabilidade foram, em sua maioria, conduzidas pelos mesmos stakebolders durante as reuniões, o que sinaliza baixa participação dos demais.

PALAVRAS-CHAVE: Câmara setorial; Carne bovina; Dimensões; Sustentabilidade.

\footnotetext{
Docente Adjunta Universidade Federal de Mato Grosso do Sul (UFMS), Campo Grande (MS), Brasil.

** Doutroranda pelo Programa de Pós-Graduação stricto sensu em Desenvolvimento Sustentável da Universidade de Brasília (PPG-CDS), Brasil.

${ }^{* * *}$ Doutora em Agronegócios; Empresa Brasileira de Pesquisa Agropecuária (EMBRAPA), Brasil.

${ }^{* * * *}$ Empresa Brasileira de Pesquisa Agropecuária (EMBRAPA GADO DE CORTE), Campo Grande (MS), Brasil.

${ }^{* * * * *}$ Graduados em Gestão de Agronegócios na Universidade de Brasília (UnB), Brasil.

${ }^{* * * * * *}$ Graduados em Gestão de Agronegócios na Universidade de Brasília (UnB), Brasil.
} 


\section{STAKEHOLDERS OF SUSTAINABLE LIVESTOCK IN BRAZIL}

ABSTRACT: Sustainability concerns and goals, mainly established due to international events, became visible in general policies and in government structure. Efforts to link political discourses with sustainability are notorious. What society desires is practices for a world in which sustainability at all levels is acknowledged, discussed and respected. This paper aims to identify relevant discussions related to sustainability and stakeholders in the Brazilian Beef Chain Sectorial Chamber during five years. A qualitative analysis on dialogues and activities in the Sectorial Chamber has been undertaken through content analysis, which defines a priori categories from literature review. The minutes of 16 out of 18 meetings held during the period were analyzed. Results indicates a greater concern on the ecology of sustainability, whereas other issues were slightly or never discussed. Analysis of the minutes shows that the theme was already defined in the agendas and clearly helped understand the issues debated during the meetings. Discussions on all issues on sustainability were largely conducted by the same stakeholders during the meetings with low participation rates of the others.

KEY WORDS: Sectorial chamber; Beef; Dimensions; Sustainability.

\section{INTRODUÇÃO}

Desde o século XX a sociedade vem enfrentando problemas decorrentes dos efeitos das mudanças climáticas. As organizações do agronegócio que buscam manter-se no mercado terão que explorar novas alternativas para manterem suas estruturas.

Os conflitos gerados pelas mudanças climáticas e falta de sustentabilidade estão preocupando stakebolders de todos os continentes, os quais fazem pressões nas organizações para que haja resoluções favoráveis ao meio ambiente. Stakebolders são indivíduos ou organizações que afetam ou são afetados por objetivos ou problemas. Resoluções que sejam construídas conjuntamente com os stakebolders das cadeias produtivas do agronegócio e não somente impostas como normas legais (AZEVEDO, 2010).

É importante salientar que na definição apresentada por Clarkson (1995), 
stakebolders são pessoas ou grupos que têm interesses em uma organização e em suas atividades no passado, presente e futuro ao passo que interesses, resultados de transações e ações das empresas sejam legal ou moral, individual ou coletiva. Ainda os stakeholders são agentes que possuem interesses similares, podendo ser classificados como fornecedores, consumidores, empregadores, dentre outros.

A participação dos diversos stakebolders nos debates ambientais favoreceu a discussão de novos temas em níveis locais, nacionais e internacionais (BRASIL, 2005). Cabe salientar que o comportamento individual representa um fator crítico na mudança climática global, e não apenas as responsabilidades atribuídas à poluição industrial, a falhas de governo ou a ineficiências das instituições (FIQUERES; IVANOVA, 2005).

A abordagem interdisciplinar, uma das prerrogativas da sustentabilidade, é um de seus aspectos mais importantes, uma vez que visa incluir diversas áreas do conhecimento no debate em busca do desenvolvimento sustentável. Um de seus elementos cruciais é, sem dúvida, o esforço de promover um entrosamento dos olhares econômico e social com a dimensão ambiental (BURSZTYN; BURZTYN, 2013). Os reflexos dessas discussões são notáveis, inclusive, na política em geral e nas estruturas de governo; vê-se muito esforço em vincular discursos políticos com a noção da sustentabilidade, bem como a necessidade de impressionar a opinião pública por meio de imagem ecologicamente correta de algumas entidades corporativas (BURSZTYN; BURZTYN, 2013). O que a sociedade realmente anseia é pela prática do discurso, por ações que visem o desenvolvimento sustentável para fora das universidades e centros de pesquisa, por um mundo em que as dimensões da sustentabilidade sejam reconhecidas, discutidas e respeitadas.

O objetivo principal deste artigo consiste em identificar e analisar os principais diálogos relacionados à sustentabilidade e os stakebolders no âmbito da Câmara Setorial da Cadeia Produtiva da Carne Bovina no Brasil nos últimos cinco anos, em especial a Bovinocultura de Corte Sustentável no País. Para tanto, as fontes de dados utilizadas na análise são dos órgãos oficiais brasileiros, incluindo especialmente as Atas das reuniões realizadas no âmbito da Câmara Setorial da Cadeia Produtiva da Carne Bovina organizadas pelo Ministério da Agricultura, Pecuária e Abastecimento (MAPA) no período 2010-2015.

\section{REFERENCIAL TEÓRICO}


Nesta seção, serão abordados temas que suportarão a discussão em torno da temática da sustentabilidade na Câmara Setorial da Cadeia Produtiva da Carne Bovina. Na primeira parte, o presente capítulo trata de apresentar as discussões que deram origem à noção de desenvolvimento sustentável e as dimensões da sustentabilidade. Em seguida, é apresentada a Teoria de Stakebolders como suporte teórico para alcançar o que se pretende com esse estudo.

\subsection{DIMENSÕES DA SUSTENTABILIDADE}

O termo Sustentabilidade, a partir do conceito abrangente definido pelo Relatório Brundtland, é multidisciplinar, polissêmico e, desta forma, aplicável a várias situações e para atender diferentes objetivos. Desta forma, diversos estudiosos buscam definir e refinar sua visão em torno do tema, como é o caso de Ignacy Sachs (1993), que define cinco dimensões para a sustentabilidade, quais sejam: a sustentabilidade social, econômica, ecológica, espacial e cultural. Posteriormente, Sachs (2000) acrescentou mais uma dimensão ao rol anteriormente proposto: a dimensão política da sustentabilidade. Além de Sachs, outros autores trabalham as dimensões da sustentabilidade, tais como Cavalcanti (2004), Novaes (2000), Drummond (1996), Costabeber e Caporal (2002), Pires (1998), Soares et al. (2006), Mantovaneli Junior e Sampaio (2007), Magalhães (2011), Guimarães (1997) e outros.

A dimensão social da sustentabilidade preocupa-se com o bem-estar humano, em busca da promoção da cidadania e da melhoria da qualidade de vida, o que abrange a desigualdade social que pode ser observada em todo o mundo; essa dimensão busca alcançar um patamar razoável de homogeneidade social por meio de distribuição de renda justa (SACHS, 1993; 2008). Para esta dimensão, o ser humano é o agente do desenvolvimento sustentável, aquele que se empenha para a conservação dos recursos naturais, que somente adquire significado e relevância quando o produto desse esforço é equitativamente aproveitado e usufruído pelos diversos segmentos da sociedade (COSTABEBER; CAPORAL, 2002). Desta maneira, o ser humano tem a capacidade de se organizar e participar dos processos de tomada de decisão para melhorar a sua qualidade de vida.

A dimensão econômica da sustentabilidade se preocupa com as 
questões relativas à responsabilidade social das empresas e necessidade de geração de emprego e renda, além da discrepância na concentração de bens e riqueza, e a questão relacionada ao planejamento governamental em busca de maior eficiência para alocação e fluxo de recursos; para essa dimensão da sustentabilidade, a eficiência econômica não pode ser medida apenas por meio de rentabilidade no sentido microeconômico, devendo ser avaliada também em termos macrossociais (SACHS, 1993; 2008). Essa dimensão é alcançada por meio de uma gestão mais eficiente dos recursos e por um fluxo regular do investimento público e privado (MAGALHÃES, 2011). Para essa dimensão, podem ser incluídas iniciativas relacionadas à diversificação de atividades produtivas e desenvolvimento intersetorial equilibrado, além de segurança alimentar, contínua modernização dos instrumentos de produção, acesso à ciência e tecnologia, e a inserção soberana das nações na economia internacional (SACHS, 2000).

A dimensão ecológica da sustentabilidade busca alcançar o denominador comum entre desenvolvimento e preservação da natureza e da biodiversidade, através da utilização de tecnologias limpas nos processos produtivos, e a qualidade ambiental; preocupa-se com a conservação e uso racional dos recursos naturais consumidos nos processos produtivos (SACHS, 1994; 2008). Já a dimensão espacial da sustentabilidade refere-se à busca de maior equilíbrio na configuração ruralurbana, com uma melhor distribuição territorial dos assentamentos humanos e das atividades econômicas (SACHS, 1993). Deve-se buscar, portanto, reduzir a concentração excessiva nas áreas metropolitanas; promover a agricultura e a exploração agrícola das florestas através de técnicas modernas, regenerativas, com o uso de pacotes tecnológicos adequados, crédito e acesso a mercados; frear a destruição de ecossistemas frágeis; entre outros (SACHS, 1993).

A dimensão cultural da sustentabilidade diz respeito à necessidade de preservação das raízes culturais dos povos, buscando-se evitar conflitos culturais, uma vez que a base do desenvolvimento reside na manutenção da diversidade em seu sentido mais amplo (SACHS, 1993; GUIMARÃES, 1997).

Por fim, a dimensão política da sustentabilidade diz respeito ao reconhecimento do papel central das autoridades locais, comunidades e associações de cidadãos, na participação do planejamento local das ações direcionadas à região 
onde vivem. Sachs (2000) e Soares et al. (2006) acrescentam que esta dimensão diz respeito à orientação política, capacidade e esforço despendido pela sociedade organizada para as mudanças necessárias para uma efetiva implantação do desenvolvimento sustentável.

Para além da definição das dimensões, é importante considerar a integração entre elas, sendo esta condição fundamental para o desenvolvimento sustentável. Cada dimensão possui suas características, condicionando e estando condicionada às demais dimensões, de modo que elas estão sujeitas a interações que devem ser consideradas no processo, podendo ser tão importantes como os componentes principais de uma dimensão considerada (SEPULVEDA, 2005). Deve haver equilíbrio entre as várias dimensões da sustentabilidade para que ocorra o processo do desenvolvimento sustentável.

\subsection{TEORIA DE STAKEHOLDERS}

Os trabalhos acadêmicos de Freeman (1984) contribuíram para popularizar o termo stakebolder, o qual era inicialmente empregado para a condução de firmas e gestão estratégica. De acordo com o autor, stakebolder é "qualquer grupo ou indivíduo que pode afetar ou é afetado pela realização dos objetivos da empresa" (FREEMAN, 1984, p. 46). Essa abordagem teórica considera potenciais interessados na atividade da empresa, além dos funcionários, acionistas, fornecedores, governo e clientes, de forma a reconhecer, analisar e examinar as características desses indivíduos e/ou grupos (CLARKSON, 1995). As definições sobre o que é um stakebolder variam da mais ampla possível até a mais restrita, de modo que se abre a possibilidade de identificar qualquer agente como stakebolder, dependendo unicamente do enfoque do pesquisador e do objetivo da pesquisa (BREEMERS; OMTA; HAVERKAMP, 2004; AZEVEDO, 2010).

Os principais objetivos em pesquisas com stakebolders têm sido identificar quem são os stakebolders de determinada empresa, e qual a influência que cada um deles exerce (LYRA; GOMES; JACOVINE, 2009). Ainda de acordo com os autores, visualizar o poder e a influência dos stakebolders tem impacto primordial no sucesso ou fracasso de um projeto, o que auxilia a definição de estratégias por parte 
da empresa de modo a construir uma imagem mais coerente e consistente.

No campo ambiental, existem pesquisas que afirmam que a inclusão de conhecimentos e perspectivas dos stakebolders no ponto de vista dos problemas ambientais têm resultado em desenvolvimento de políticas e pesquisas diferenciadas (KLOPROGEE; VAN DER SLUJS, 2006). Para este trabalho, são considerados stakebolders os participantes das reuniões e discussões na Câmara Setorial da Cadeia Produtiva da Carne Bovina, e a sua identificação contribuirá para levantar a participação de cada um deles nas referidas câmaras setoriais de modo a perceber suas contribuições para a discussão em torno da sustentabilidade.

\section{MATERIAL E MÉTODO}

Trata-se de um estudo descritivo, com abordagem qualitativa. Foi utilizada a técnica de pesquisa documental para coleta dos dados secundários, a qual teve por base a fonte oficial da Câmara Setorial da Cadeia Produtiva da Carne Bovina (MAPA, 2015).

Os dados foram analisados segundo o método da Análise de Conteúdo, segundo Bardin (2006, p. 38). Para tanto, existem diversos procedimentos os quais o pesquisador pode fazer uso como a análise léxica, a análise de categorias, a análise de enunciação e a análise de conotações (CHIZZOTTI, 2006).

O processo de análise dos dados a partir da técnica da Análise de Conteúdo é constituído por três etapas definidas por Bardin (2006): 1) pré-análise; 2) exploração do material; e 3) tratamento dos resultados, inferência e interpretação.

Para este trabalho, as categorias de análise são definidas a priori, à luz da literatura, em função de já terem sido delineadas nos trabalhos de Ignacy Sachs (1993) as dimensões da sustentabilidade. São elas: espacial, cultural, política, ecológica, econômica e social.

Foram analisadas as atas das reuniões da Câmara Setorial da Cadeia Produtiva da Carne Bovina ocorridas entre os anos de 2010 e 2015. Inicialmente, a pretensão era de realizar a análise de todas as atas de reuniões ocorridas desde a fundação da Câmara Setorial, mas, em função da grande quantidade de documentos a ser 
analisada, o horizonte temporal foi limitado e estabelecido o recorte dos últimos cinco anos, a fim de levantar as discussões mais atuais. Foi necessária a solicitação, via telefone e e-mail, de envio por parte dos secretários da Câmara Setorial da Carne Bovina de atas de reuniões que não estavam disponíveis no endereço eletrônico de acesso ao histórico das atas. O secretário foi solícito e atendeu à demanda das autoras com brevidade.

No total, foram analisadas 16 atas de reuniões da Câmara Setorial da Carne Bovina, ocorridas entre os anos de 2010 e 2015. Os autores não tiveram acesso às atas da $26^{\mathrm{a}}$ e $35^{\mathrm{a}}$ reuniões da Câmara Setorial da Carne Bovina, uma vez que não estavam disponíveis no endereço eletrônico das Câmaras Setoriais, e tampouco foram localizadas pelo secretário das Câmaras. Essas atas não foram, portanto, analisadas.

\section{RESULTADOS E DISCUSSÕES}

A Câmara Setorial da Cadeia Produtiva de Carne Bovina foi instalada em $1^{\circ}$ de maio de 2003, na cidade de Ribeirão Preto (SP). A primeira reunião da Câmara ocorreu em Brasília no dia 27 de maio de 2003. A Câmara é constituída oficialmente por 42 instituições e teve sua criação publicada no Diário Oficial da União do dia 28 de novembro de 2003, alterada pela Portaria $\mathrm{n}^{0} 15$, de 05 de janeiro de 2006. Entre os anos de 2010 e 2015, os membros desta Câmara se reuniram 18 vezes, das quais foram analisadas atas de 16 reuniões nesta pesquisa.

Com relação à composição da Câmara Setorial da Cadeia Produtiva da Carne Bovina citam-se os seguintes membros efetivos: ABCZ (Associação Brasileira dos Criadores de Zebu), ABIEC (Associação Brasileira das Indústrias Exportadoras de Carne), ABRAFRIGO (Associação Brasileira de Frigoríficos), ABRAS (Associação Brasileira de Supermercados), ASBRAER (Associação Brasileira das Entidades Estaduais de Assistência Técnica e Extensão Rural), ASSOCON (Associação Nacional dos Confinadores), BB (Banco do Brasil), CICB (Centro das Indústrias de Cortumes do Brasil), CNA (Confederação da Agricultura e Pecuária do Brasil), CNPC (Conselho Nacional da Pecuária de Corte), EMBRAPA (Empresa Brasileira 
de Pesquisa Agropecuária), MDIC (Ministério do Desenvolvimento, Indústria e Comércio), FAMASUL (Federação da Agricultura e Pecuária de Mato Grosso do Sul), MF (Ministério da Fazenda), SINDAN (Sindicato Nacional da Indústria de Produtos para Saúde Animal), SINDIRAÇÕES (Sindicato Nacional Industrial de Alimentação Animal), SPA/MAPA (Secretaria de Política Agrícola do Ministério da Agricultura, Pecuária e Abastecimento), SRB (Sociedade Rural Brasileira), ABEG (Associação Brasileira dos Exportadores de Gado), ABIA (Associação Brasileira das Indústrias da Alimentação), FAEP (Federação da Agricultura do Estado do Paraná), GS1 Brasil (Associação Brasileira de Automação), SNA (Secretaria Nacional de Agricultura), UNIESC, CONAB (Companhia Nacional do Abastecimento).

De todas as dimensões da sustentabilidade aqui apresentadas, a dimensão ecológica foi a mais presente nas discussões desta Câmara Setorial. Interessante perceber que, por se tratar de um produto específico (a carne bovina), as discussões em torno da dimensão ecológica da sustentabilidade perpassaram, ainda, por questões relativas ao bem-estar animal.

Em se tratando de sistemas produtivos cujo foco é a produção e obtenção de produtos de origem animal, é notável nas discussóes da Câmara Setorial a preocupação em torno de questões relativas à sanidade e saúde dos animais, além do bem-estar animal e transporte. Essas discussões se enquadram na dimensão ecológica da sustentabilidade, uma vez que também demonstram preocupações com o uso dos recursos consumidos nos processos produtivos.

O Programa de Boas Práticas Agropecuárias (BPA) para bovinos de corte foi apresentado e discutido durante as $23^{\mathrm{a}}$ e $25^{\mathrm{a}}$ reuniões ordinárias. Esse programa inclui um conjunto de normas e procedimentos a serem observados pelos produtores rurais que, além de tornar os sistemas produtivos mais rentáveis e competitivos, asseguram também a oferta de alimentos seguros, oriundos de sistemas de produção sustentáveis. Durante a $23^{a}$ reunião, um pesquisador da Embrapa Gado de Corte apresentou um panorama sobre o andamento do programa, parceiros e vantagens de sua implantação, além de um manual didático sobre o mesmo. Já na $25^{\mathrm{a}}$ reunião, o assunto foi abordado em função da falta de apoio político para consolidar os projetos e apoiar o produtor na execução do processo.

Com relação à saúde animal, foram apresentados e discutidos dois 
importantes programas de sanidade animal: o Programa Nacional de Erradicação e Prevenção da Febre Aftosa e o Programa Nacional de Controle da Brucelose. O primeiro deles foi apresentado e discutido durante a $37^{\mathrm{a}}$ reunião ordinária, onde um representante do MAPA falou sobre os avanços do programa e suas consequências, como o pleito pela inclusão da região Nordeste do país e o Estado do Pará na zona livre de febre aftosa com vacinação. O segundo programa foi apresentado durante a $29^{a}$ reunião ordinária, onde foi dito que, após 10 anos de existência, este programa passa por um processo de revisão com vistas a aumentar a sua eficiência.

Acerca de trabalhos sobre o trânsito e transporte animal, foram apresentadas as discussões na $38^{\mathrm{a}}$ e $40^{\mathrm{a}}$ reuniões ordinárias. $\mathrm{Na} 38^{\mathrm{a}}$ reunião, um representante do MAPA explicou sobre um novo Guia de Trânsito Animal, que servirá como processo de emissão de documentos conforme as regras estaduais que contêm as informações sobre o destino e as condições sanitárias, bem como a finalidade do transporte animal. Nessa mesma reunião, um representante do MAPA apresentou os andamentos de um grupo de trabalho de Regulamentação do Transporte Rodoviário de Animais de Produção, tendo sido estabelecidas duas prioridades do grupo: a estrutura do transporte e os seus requisitos mínimos. Já na $40^{\mathrm{a}}$ reunião foram prestados esclarecimentos a respeito da proposta de normas sobre Transporte Rodoviário de Cargas Vivas, elaboradas pelo grupo de trabalho responsável pelo tema, e apresentadas por um representante do MAPA. Nesta oportunidade, foi dito que na minuta final das normas constam contribuições de várias entidades, embora seja necessária a revisão com a participação de todos os segmentos da cadeia.

Além dessas questões, o Plano Setorial de Mitigação e Adaptação às Mudanças Climáticas para a consolidação de uma economia de baixa emissão de carbono na agricultura, o Plano ABC, foi apresentado e discutido em três das 16 reuniões analisadas. Este Plano tem por finalidade a organização e o planejamento das ações a serem realizadas para a adoção de tecnologias de produção sustentáveis, selecionadas com o objetivo de responder aos compromissos de redução da emissão de gases de efeito estufa no setor agropecuário assumidos pelo país. Durante a $23^{\mathrm{a}}$ reunião, uma representante do MAPA apresentou o Plano $\mathrm{ABC}$ e delineou acerca dos seus objetivos e desafios. $\mathrm{Na} 24^{\mathrm{a}}$ reunião, foi novamente apresentado o Plano, e ainda as suas estratégias de ação por meio de seus subprogramas, que 
são sete, para a sua implementação. Já na $29^{a}$ reunião, houve uma solicitação de inclusão da tecnologia de confinamento nas linhas de financiamento e crédito do Programa. Houve um informe, durante a $23^{a}$ reunião ordinária da Câmara, acerca do III Simpósio ABCZ/CNPC de Pecuária Sustentável, o qual ocorreu em Uberaba (MG) e contou com a presença de 150 pessoas, incluindo o Grupo de Trabalho (GT) da Pecuária Sustentável. Este GT, criado no final do ano de 2007, formalmente constituído em 2009, é formado por representantes de diferentes segmentos que integram a cadeia produtiva da bovinocultura de corte no Brasil, quais sejam: indústrias, associações de pecuaristas, varejistas, bancos, organização da sociedade civil, centros de pesquisa e universidades. Seu objetivo é debater e formular, de maneira transparente, princípios padrões e práticas comuns a serem adotados pelo setor, que contribuam para o desenvolvimento de uma pecuária sustentável socialmente justa, ambientalmente correta e economicamente viável. O GT e todos os seus membros assumiram compromisso com o desmatamento zero, com a criação de condições e formas de compensação para viabilizá-lo. Para cumprir com esse compromisso, o GT se compromete a desenvolver ferramentas e mecanismos para o monitoramento, rastreamento, critérios de produção, compra e financiamento, e incentivos econômicos para a promoção da sustentabilidade na pecuária bovina. Um representante do CNPC discorreu sobre o Simpósio, afirmando que durante o evento foram apresentados diversos trabalhos acerca da emissão de gases de efeito estufa em sistemas de produção de bovinos de corte.

A Câmara Setorial manifestou, durante a $23^{\mathrm{a}}$ reunião ordinária, apoio oficial para a execução do projeto "Em defesa da pecuária sustentável", que tem como objetivo desenvolver estudos sobre as críticas que a cadeia produtiva da carne bovina tem sofrido, com foco especial em questões ambientais e de bem-estar animal. Uma representante do MAPA informou que o Ministério se prontificou a oferecer parte dos recursos, juntamente com o MDIC e o MCT, além da CNA que também manifestou a possibilidade de contribuir.

O Projeto PECUS (Dinâmica de gases de efeito estufa em sistemas de produção da agropecuária no Brasil), conduzido pela EMBRAPA, foi apresentado durante a $25^{\text {a }}$ reunião ordinária. Na oportunidade, uma representante da EMBRAPA afirmou que o projeto é composto por uma rede de pesquisa destinada a avaliar 
a emissão de gases de efeito estufa pela pecuária, sendo o balanço da atividade o foco da pesquisa, uma vez que além da emissão do metano, também ocorre o seu sequestro no processo produtivo. Além disso, ela explicou que as emissões de metano são naturais, porém podem ser diminuídas melhorando a qualidade da dieta a que o animal é submetido, bem como os seus hábitos.

Um panorama sobre a Primeira Reunião Global Sobre Pecuária Sustentável foi apresentado durante a $27^{\mathrm{a}}$ reunião da Câmara, que aconteceu em parceria com o MAPA, FAO, CNA e EMBRAPA com o objetivo de desenvolver uma agenda de ação global sustentável para garantir a segurança alimentar e nutricional com o uso dos recursos naturais de forma eficiente. O relato da reunião foi conduzido por uma representante do MAPA.

O Grupo de Trabalho de Pecuária Sustentável (GTPS), uma entidade inédita na cadeia produtiva da pecuária de corte no Brasil, apresentou informes sobre o andamento de seus trabalhos durante a $32^{\mathrm{a}}$ reunião ordinária da Câmara. O grupo informou sobre a assinatura de um protocolo de intenções com o MAPA, MMA e EMBRAPA para cooperar com o Governo Federal a fim de atingir a meta de recuperar 15 milhões de hectares de áreas de pastagens degradadas. A proposta está alinhada com a Política Nacional de Mudanças do Clima.

A Agenda Global sobre Pecuária Sustentável, criada no âmbito da FAO, também foi apresentada e discutida pela Câmara Setorial da bovinocultura de corte. Uma representante do MAPA, durante a $33^{\mathrm{a}}$ reunião ordinária, fez um breve relato sobre a Agenda, comentando as reuniões que foram realizadas neste ano com o objetivo de definir o escopo e a atuação da agenda. Durante o ano foram realizados três Workshops abordando os seguintes temas: recuperação de áreas degradadas, manejo de resíduos agropecuários e dejetos de animais, e utilização eficiente dos recursos naturais. A representante do MAPA destacou a importância de o Brasil ter voz ativa neste Fórum, e que o MAPA já informou a possibilidade de aportar recursos para esta Agenda, considerando a importância da pecuária para o país.

A dimensão ecológica da sustentabilidade apresenta importância singular, conforme corrobora Magalhães $(2011$, p. 78) ao afirmar que esta é fundamental para o alcance do desenvolvimento sustentável, principalmente por ser "um conceito que busca se contrapor àquela visão tradicional - ou modelo tradicional de exploração 
econômica - que tem como base o curto-prazo e o uso ilimitado e indiscriminado dos recursos naturais e produtivos".

No tocante à dimensão política da sustentabilidade, foram observadas ações principalmente em relação à solicitação de inclusão de novas entidades na Câmara Setorial, além de serem apresentados relatórios periódicos acerca de entidades faltantes e composição da Câmara. Ações como estas se encaixam na dimensão política da sustentabilidade uma vez que "concebendo o espaço como social, concebemos também a participação da sociedade como fundamental para as tomadas de decisões" (SILVA, 2011). Espaços de participação social, como o caso das Câmaras Setoriais, além de associações, conselhos municipais, foros de debate, dentre outros, "representam a pressão político-social exercida pela sociedade civil em querer ser ouvida e participar junto às decisões e ações" (SILVA, 2011).

Durante a $30^{\mathrm{a}}$ reunião ordinária, foi solicitada pela Confederação Nacional dos Municípios (CNM) e a Associação Brasileira de Exportadores de Gado (ABEG) a entrada na Câmara Setorial como convidados especiais e, após breves informações prestadas pelas interessadas, o pleito foi aceito pelo plenário. O mesmo ocorreu durante a $39^{\mathrm{a}}$ reunião, quando a Associação Brasileira das Indústrias da Alimentação (ABIA) solicitou entrada para compor a Câmara como convidada especial, condição esta que foi aprovada pelos membros presentes.

Ainda discorrendo sobre ações no âmbito da dimensão política da sustentabilidade, foi sugerida durante a $31^{\mathrm{a}}$ reunião a criação de um GT para elaborar propostas de arranjos produtivos, como alianças mercadológicas, entre produtores, indústria, varejo e demais elos da cadeia produtiva, com o objetivo de promover um aumento na agregação de valor e melhor distribuição dos ganhos em toda a cadeia. Foi decidido que será convocada uma reunião para elaboração de uma proposta preliminar.

Durante a $33^{\mathrm{a}}$ reunião ordinária foi decidido sobre o agendamento de audiência com o MAPA com o objetivo de apresentar o Projeto PECUS, sua importância para a cadeia produtiva e solicitar gestões da Secretaria de Desenvolvimento Agropecuário e Cooperativismo junto aos Fundos Setoriais pertinentes para a liberação dos recursos necessários à sua execução.

Foi apresentado um quadro de frequência e levado à apreciação dos 
membros da Câmara, para que pudessem discutir sobre a situação de entidades faltosas, durante a $34^{\mathrm{a}}$ reunião ordinária. $\mathrm{O}$ mesmo foi feito durante a $38^{\mathrm{a}}$ reunião; em ambas as ocasiões foi destacado que as entidades que tiveram frequência irregular estão passíveis de exclusão de acordo com o Regimento Interno das Câmaras. Foi dito, porém, que o que se pretende não é a exclusão das entidades, e sim que todas tenham participação efetiva, contribuindo com os trabalhos da Câmara para o fortalecimento do setor e, desta forma, foi sugerido que a regra não fosse aplicada neste momento. $\mathrm{O}$ assunto foi novamente abordado na $40^{\mathrm{a}}$ reunião, oportunidade na qual foi apresentada a nova composição da Câmara, destacando as entidades faltantes e reincidentes. Após discussão, o plenário concordou com a exclusão de entidades faltosas, a menos que alguma delas manifeste interesse em retomar participação nas reuniões. A FAEG (Federação da Agricultura e Pecuária de Goiás) e a CONAB solicitaram inclusão na Câmara, e foram aceitas pelo plenário.

Foram prestadas informações, durante a $34^{\mathrm{a}}$ reunião ordinária, acerca dos Seminários do Agronegócio para Exportação, por representantes do MAPA. Na oportunidade, foi dito que o seu objetivo é disseminar informações estratégicas para o aumento da inserção do agronegócio brasileiro no mercado internacional. Estes são realizados em todas as regiões do país, disseminando as informações pertinentes entre produtores rurais, sindicatos rurais, associações, cooperativas, agroindústrias, distribuidores e instituições de apoio do agronegócio.

Foi solicitado apoio durante a $37^{\mathrm{a}}$ reunião para a estruturação do Centro da Inteligência da Carne, uma proposta de sistematização de dados e informações da cadeia produtiva da carne bovina, que se propõe a buscar, organizar e disponibilizar dados e informações de acordo com as principais demandas da cadeia. A expectativa é que este Centro facilite o acesso à informação para todos os stakebolders da cadeia da carne bovina, sendo uma ferramenta moderna e confiável de acesso público. O Centro é de iniciativa da EMBRAPA Gado de Corte, e recebeu apoio da Câmara Setorial, sendo destacado que esta pode ser uma oportunidade para concretizar os dados e informações de que os stakebolders tanto necessitam.

No tocante às demais dimensões da sustentabilidade, percebeu-se uma preocupação menos intensa, principalmente com relação às dimensões social e cultural. Não foram discutidas em nenhuma das reuniões da Câmara nos últimos 
cinco anos ações em torno dessas dimensões; com relação às dimensões social e espacial, foram discutidas ações em duas das reuniões, enquanto que para a dimensão econômica, foi discutida apenas uma ação em uma reunião ordinária.

Acerca da dimensão econômica da sustentabilidade, durante a $32^{\mathrm{a}}$ reunião ordinária da Câmara Setorial, foi apresentado por um representante do MAPA o crédito de investimento alocado no Programa $\mathrm{ABC}$, visando financiar a implantação e ampliação de sistemas de integração lavoura-pecuária-floresta e demais práticas conservacionistas envolvendo uma produção sustentável do ponto de vista social e ambiental, direcionando uma baixa emissão de gases de efeito estufa na agricultura. Para a safra vigente à época da reunião, foram alocados $\mathrm{R} \$ 3,4$ bilhões, sendo $\mathrm{O}$ limite de financiamento por beneficiário de $\mathrm{R} \$ 1$ milhão com taxa de juros reduzida e com prazo de reembolso de 5 a 15 anos de acordo com o projeto.

Uma das ferramentas operacionais do Plano $\mathrm{ABC}$ é de suma importância para o atingimento das metas do Plano e do compromisso voluntariamente assumido pelo país na Conferência de Copenhague em 2009. Essa ação se enquadra na dimensão econômica da sustentabilidade porque demonstra preocupação com a questão relacionada ao fluxo regular de investimento público e privado, levando em conta que, "ao se considerar a viabilidade econômica de qualquer iniciativa que altere significativamente o meio ambiente, não pode ocorrer isoladamente quando se trata de desenvolvimento sustentável, necessitando de uma interação com critérios de sustentabilidade ambiental" (MAGALHÃES, 2011, p. 79). Essa dimensão da sustentabilidade engloba a diversificação de atividades produtivas e um desenvolvimento intersetorial equilibrado, segurança alimentar, contínua modernização dos instrumentos de produção e acesso à ciência e tecnologia (SACHS, 2000).

Em se tratando da dimensão espacial da sustentabilidade, foi apresentada por um pesquisador da EMBRAPA, durante a $24^{\mathrm{a}}$ reunião da Câmara, uma palestra sobre os fatores de crescimento da pecuária de corte e a economia de recursos naturais. Na oportunidade, o pesquisador afirmou que este estudo, conduzido pela EMBRAPA, permite concluir que a expansão da produção de carne bovina no país tem sido explicada predominantemente por ganhos em produtividade. Para se ter uma ideia, entre os anos de 1970 e 2006, os ganhos em produtividade explicaram 
cerca de $87 \%$ da expansão da produção, e o aumento na área de pastagens explicou menos de $13 \%$ do aumento da produção. Tais ganhos de produtividade possibilitaram efeito poupa-terra expressivo e da ordem de 340 milhões de hectares, de acordo com o pesquisador. A análise de estatísticas oficiais disponíveis permite concluir que a pecuária nacional já vem buscando o caminho da sustentabilidade há décadas, e que esse esforço do setor tem produzido significativos benefícios ambientais para a sociedade. Ações como esta se enquadram na dimensão espacial da sustentabilidade por demonstrarem uma preocupação com relação à busca de equilíbrio na configuração rural-urbana e a melhor distribuição territorial das atividades econômicas e produtivas (MENDES, 2009).

Ainda dentro dessa dimensão, foram discutidos e apresentados cenários para a cadeia produtiva da carne bovina a partir do novo Código Florestal, durante a $31^{\mathrm{a}}$ reunião ordinária. Quem conduziu a discussão foi um representante da CNA, que apresentou ao plenário um panorama do Código Florestal, destacando a questão de consolidação de uso das áreas de preservação permanente (APP) como a principal questão a ser negociada no Congresso Nacional, especialmente no que se refere às margens dos rios. Um representante da EMBRAPA lembrou que ainda não há condições técnicas para implementação das medidas de solução dos passivos ambientais, seja na iniciativa privada, seja por parte do poder público, e que isso deve gerar um enorme passivo judicial. De acordo com ele, o tema é complexo e, por isso, a EMBRAPA não tem sido capaz de oferecer soluções a todos os problemas.

Percorrer novos rumos em direção a um desenvolvimento mais inclusivo e responsável é uma tarefa complexa e que, quando envolve mais de um ator, pode apresentar diferenciais competitivos, uma vez que se pode contar com as sinergias decorrentes das interações entre os stakebolders, contribuindo de maneira positiva para todo esse processo. O caráter sistêmico da cadeia produtiva, por si só, já é característica que pressupõe a interação entre os atores, de modo a colaborar para o desenvolvimento e fortalecimento das atividades e coordenação da cadeia.

É notável o esforço de alguns membros da Câmara Setorial da cadeia produtiva da carne bovina em levar para as reuniões questões atuais em busca da competitividade da cadeia como um todo, além de assuntos relacionados à questão ambiental. A atuação dos diversos stakeholders nas discussões certamente contribui 
para o fortalecimento da cadeia produtiva, o que é convertido em ações que buscam a integração entre os atores.

Assuntos e ações envolvendo a dimensão ecológica da sustentabilidade foram discutidos em 10 das 16 reunióes, o que demonstra a preocupação dos stakebolders com a temática envolvendo a questão ambiental. As outras dimensões, porém, foram pouco ou nada discutidas, de modo que estas devem ser questões pouco prioritárias na agenda de discussão desta Câmara Setorial.

O objetivo de reunir diversos atores de uma cadeia produtiva para debater assuntos de interesse da cadeia é inovadora e, ao menos inicialmente, parece ter despertado o interesse de diversos stakebolders. Percebeu-se, porém, que as discussões em torno de todas as questões envolvendo a sustentabilidade foram, em sua maioria, conduzidas pelos mesmos stakebolders durante as reuniões, o que sinaliza baixa participação dos demais.

\section{CONSIDERAÇÕES FINAIS}

O objetivo deste estudo foi o de identificar as principais discussões em torno da temática da sustentabilidade e os stakebolders que as conduzem na Câmara Setorial da Cadeia Produtiva da Carne Bovina no Ministério da Agricultura, Pecuária e Abastecimento (MAPA) no Brasil.

Percebeu-se com essa pesquisa o esforço em se integrar os diversos stakebolders da cadeia produtiva da carne bovina em torno de questões que são estratégicas para toda a cadeia. A Câmara Setorial se reuniu, em média, 4 vezes ao ano durante os últimos cinco anos, prazo considerado para a análise desta pesquisa, e em grande parte das reuniões foram abordados assuntos envolvendo ao menos uma dimensão da sustentabilidade.

Foi identificado que a dimensão ecológica foi muito mais debatida durante as reuniões do que as outras dimensões da sustentabilidade aqui estudadas. Isso é preocupante, uma vez que a sustentabilidade não pode ser resumida em apenas uma dimensão; pelo contrário, é necessário que todas as dimensões estejam integradas e em interação.

Uma questão emergiu ao longo do desenvolvimento desta pesquisa, 
direcionando a uma aparente incoerência, a saber: o que explica a discussão e debate de questões em torno de apenas uma dimensão da sustentabilidade? A pauta das reuniões já apresentava os assuntos a serem debatidos em cada reunião e, possivelmente, esse foi um importante viés a ser considerado na análise dos resultados dessa pesquisa. Além disso, os resultados apontam para uma possível confusão conceitual e, em função dela, os stakebolders parecem relacionar apenas a questão ambiental - dimensão ecológica - com a noção de sustentabilidade.

Tendo em vista os resultados da pesquisa, o que se recomenda é que sejam levados para as reuniões assuntos que demonstrem preocupações e ações em torno das dimensões da sustentabilidade para além da ecológica, uma vez que somente a questão ambiental é insuficiente para que se alcance o desenvolvimento sustentável. Envolver discussões em torno das temáticas social, econômica, espacial, cultural e política certamente contribuirá para o aprimoramento e competitividade de toda a cadeia produtiva.

Em função da agregação de diversas entidades de importância singular, não somente para a cadeia produtiva da carne bovina, como para o agronegócio brasileiro como um todo, o potencial das discussões e ações desta Câmara Setorial ainda deve ser mais bem perseguido e explorado.

O país ainda está tentando unir em um mesmo fórum de discussões algumas iniciativas e propostas das entidades em busca da proposição de uma linha de ação mais concreta onde todos os agentes (stakebolders) da cadeia estejam coordenados.

Como limitação da pesquisa e também sugestão para continuação de trabalhos futuros está a possibilidade de análise de conteúdo textual das atas das reuniões, bem como o cruzamento desses resultados obtidos com a análise dos dados da Câmara Setorial da Carne Bovina com as demais Câmaras correlatas, como Soja, Milho, dentre outras. Essa análise integrada permite a maior riqueza de detalhes e a verificação de possíveis inter-relações e interfaces de ações conjuntas, relevantes para identificação de propostas e/ou resultados de políticas públicas para o desenvolvimento do agronegócio brasileiro de forma sustentável.

\section{REFERÊNCIAS}


AZEVEDO, D. B. Diálogos entre Stakebolders em redes de organizações de agronegócios na busca da mititgação dos efeitos climáticos: o caso do instituto para agronegócio responsável, ARES. Tese (Doutorado em Agronegócios) - Universidade Federal do Rio Grande do Sul, Porto Alegre, 2010. Disponível em: $\quad<$ http://www.lume.ufrgs.br/bitstream/handle/10183/24508/000746060. pdf?sequence $=1>$ Acesso em: 20 mar. 2013.

AZEVEDO, D. B. et al. The inclusion of stakeholders in the coordination of problems decurrent from climatic changes in agribusiness. In: INTERNACIONAL PENSA CONFERENCE, 6., 2007, Ribeirão Preto. Proceedings... Ribeirão Preto: USP, 2007.

BARDIN, L. Análise de conteúdo. Lisboa: Edições 70, 2006.

BRASIL. Empresa Brasileira de Pesquisa Agropecuária. Emissão de metano pela pecuária. 2008. Disponível em: <http://www.socioambiental.org/banco_imagens/ pdfs/magda_lima.pdf $>$. Acesso em: 20 ago. 2015.

BRASIL. Instituto Brasileiro de Geografia e Estatística. Efetivo dos rebanhos. 2010. Disponivel em: <http:/www.ibge.gov.br/home/presidencia/noticias/noticia visualiza.php?id_noticia=1761\&id_pagina=1 > Acesso em: 17 jul. 2012.

BRASIL. Ministério do Meio Ambiente. Efeito estufa e aquecimento global. 2012. Disponível em: <http://www.mma.gov.br/clima/ciencia-da-mudanca-do-clima/ efeito-estufa-e-aquecimento-global > . Acesso em: 16 ago. 2012.

BREMMERS, H.; OMTA, D. J.; HAVERKAMP, O. A stakeholder view on sustainable food and agribusiness chain development. 2004. Disponível em: $<$ http.ifama. org/conferences/2004conference/papers.htm > . Acesso em: 08 ago. 2015.

BURSZTYN, M. A.; BURSZTYN, M. Fundamentos de política e gestão ambiental: caminhos para a sustentabilidade. Rio de Janeiro: Garamond, 2012.

CAVALCANTI, C. Uma tentativa de caracterização da economia ecológica. Ambiente e sociedade, Campinas, v. 7, n. 1, p. 149-156, 2004. Disponível em: < http://www. scielo.br/pdf/asoc/v7n1/23541.pdf> Acesso em: 10 nov. 2015. 
CHIZZOT'TI, A. Pesquisa em ciências humanas e sociais. 8. ed. São Paulo: Cortez, 2006.

CLARKSON, M. B. E. A stakebolder framework for analysing and evaluating corporate social performance. Academy of Management Review, Mississipi, v. 20, n. 1, p. 92 117, Jan. 1995.

COMISSÃO MUNDIAL SOBRE O MEIO AMBIENTE E DESENVOLVIMENTO. Relatório Brundtland: nosso futuro comum. 2. ed. Rio de Janeiro: Fundação Getúlio Vargas, 1991.

COSTABEBER, J. A.; CAPORAL, F. R. Análise multidimensional da sustentabilidade: uma proposta metodológica a partir da agroecologia. Agroecologia e Desenvolvimento Rural Sustentável, Porto Alegre, v. 3, n. 3, p. 70-85, 2002. Disponível em: <http://www.reformaagrariaemdados.org.br/sites/default/files/ Analise\%20multidimensional\%20da\%20sustentabilidade,\%20uma\%20proposta\%20 metodologica $\% 20$ a $\% 20$ partir\%20da\%20agroecologia\%20-\%20Francisco $\% 20$ Caporal,\%20Jose\%20Costabeber.pdf> Acesso em: 12 nov. 2015.

DRUMMOND, J. A. A extração sustentável de produtos florestais na Amazônia Brasileira. Estudos - sociedade e agricultura, Rio de Janeiro, v. 6, p. 116-137, 1996.

FIGUERES, C.; IVANOVA, M. H. Mudanças climáticas: interesses nacionais ou um regime global? In: ESTY, D.; INAVONA, M. H. (Org.). Governança ambiental global: opções e oportunidades. São Paulo: Senac, 2005.

FREEMAN, R. E. Strategic management: a stakeholder approach. Boston: Pitman; Ballinger, 1984.

FREEMAN, R. E.; EVAN, W. M. Corporate governance: a stakeholder interpretation. The Journal of Behavioral Economics, v. 19, p. 337-359, dec. 1990.

GIL, A. C. Como elaborar projetos de pesquisa. São Paulo: Atlas, 2008.

GIL, A. C. Métodos e técnicas de pesquisa social. São Paulo: UNESP, 1991. 
GOLDBERG, R. A. Agribusiness coordination: a system approach to the wheat, soybean, and Florida Orange economies. Division of Research: Harvard University, 1968.

KLOPROGEE, P.; VAN DER SLUIJS, J. P. The inclusion of stakeholder knowledge and perspectives in integrated assessment of climate change. Climate Change, Netherlands, v. 75, n. 3, p. 359-389, 2006.

LYRA, M. G.; GOMES, R. C.; JACOVINE, L. A. G. O papel dos stakeholders na sustentabilidade da empresa: contribuições para a construção de um modelo de análise. Revista de Administração Contemporânea, v. 13, 2009. Disponível em: $\quad<$ http://www.scielo.br/scielo.php?script $=$ sci_arttext\&pid=S1415$65552009000500004 \& \operatorname{lng}=$ pt\&nrm=iso\&tlng=pt $>$ Acesso em: 09 set. 2015.

MAGALHÃES, R. M. Obstáculos a exploração do baru no cerrado goiano: sustentabilidade comprometida? 2011. 264f. Tese (Doutorado em Desenvolvimento Sustentável) - Universidade de Brasília, Brasília, 2011.

MANTOVANELIJUNIOR,O.;SAMPAIO,C.A.C.Sustentabilidadepolíticaeadministrativa: contribuições para a reformulação da agenda para o ecodesenvolvimento. Revista de Gestão Social e Ambiental, Rio de Janeiro, v. 1, n. 2, p. 3-21, 2007.

MAPA. MINISTÉRIO DA AGRICULTURA, PECUÁRIA E ABASTECIMENTO. Câmaras setoriais e temáticas. 2015. Disponível em: < http://www.agricultura.gov.br/ camaras-setoriais-e-tematicas > Acesso em: 10 nov. 2015.

MENDES, J. M. G. Dimensões da sustentabilidade. Revista das Faculdades Santa Cruz, v. 7, n. 2, 2009. Disponível em: < http://www.santacruz.br/v4/download/ revista-academica/13/cap5.pdf > Acesso em: 15 set. 2015.

SACHS, I. Caminhos para o desenvolvimento sustentável. 3. ed. Rio de Janeiro: Garamond, 2008.

SACHS, I. Caminhos para o desenvolvimento sustentável. Rio de Janeiro: Garamond, 2000. 
SACHS, I. Estratégias de transição para o século XXI. In: BURSZTYN, M. (Org). Para pensar o desenvolvimento sustentável. São Paulo: Braziliense, 1993.

SEPÚLVEDA, S. Desenvolvimento sustentável microrregional: métodos para planejamento local. Brasília: IICA, 2005.

SILVA, A. S. Espaço urbano, desigualdade e indicadores de dimensões da sustentabilidade: análise de Formosa-GO. 2011. 296f. Tese (Doutorado em Geografia) - Universidade Estadual Paulista, Presidente Prudente, 2011.

SILVA, S. R. M. Indicadores de sustentabilidade urbana: as perspectivas e as limitações da operacionalização de um referencial sustentável. 2000. 260f. Dissertação (Mestrado em Engenharia Urbana) - Universidade Federal de São Carlos, São Carlos.

Recebido em: 23 de agosto de 2013 Aceito em: 23 de março de 2016 